\section{Freer trade in US oranges helps Japanese researchers}

Fukuoka, Japan. Pressure to open up Japan's orange market to US farmers is hurting native growers but helping university researchers. Administrators of Kyushu University in Fukuoka city in Japan's southern island of Kyushu have begun drafting plans to move the university's main

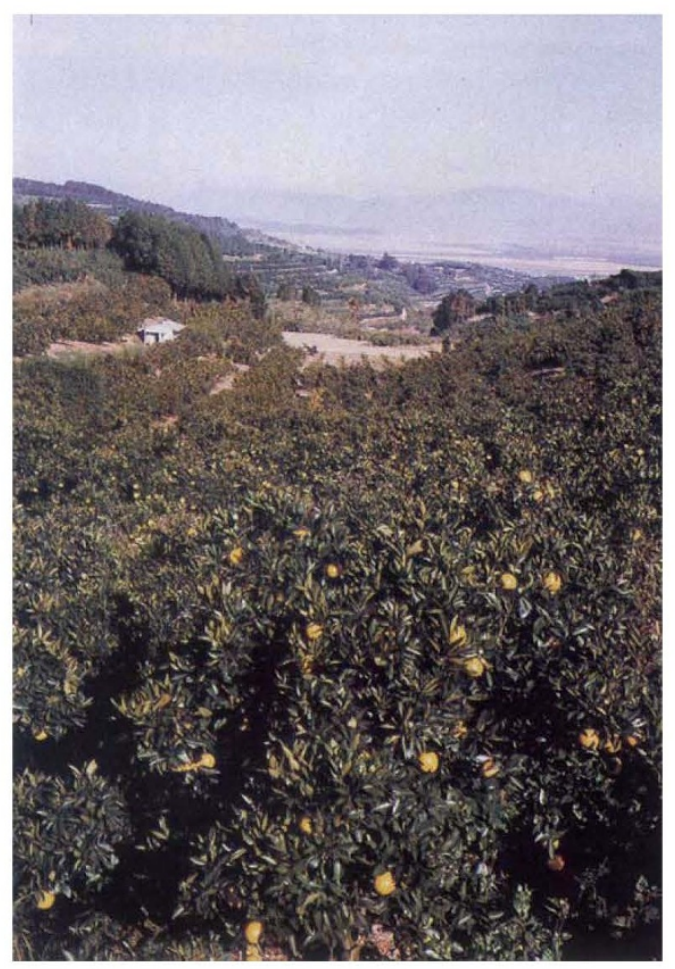

Trade policies peel off mikan farmers.

campus to a large plot in the outskirts of the city being vacated by mandarin orange (mikan) farmers put out of business by the recent liberalization of Japan's orange market.

Kyushu University is just one of Japan's leading national universities taking advantage of amended laws allowing them to use money from the sale of university land to buy land for new university campuses. The amendment, effective from July this year, is one of several changes aimed at renovating Japan's dilapidated and cramped national universities. Government neglect has created the problem, made worse by a rapid decline in the student-age population beginning this year which is forcing universities to become more competitive.

Before the amendment, money from the sale of university land was deposited in the coffers of the Ministry of Finance and could not be designated for university use. But the money will now be pooled in a fund that universities can tap for buying new land.
Kyushu University is inconveniently divided among four campuses in Fukuoka. Under the plan now being drawn up, the main Hakozaki campus near the centre of Fukuoka that houses the faculties of science, engineering, agriculture, literature, economics and education will move to the new site in the far western outskirts of Fukuoka, joining the college of general education now on a separate campus in the southwestern part of the city. The site has become available because unprofitable mikan farms are being sold following a recent US-Japanese trade agreement that has opened up Japan to a flood of US oranges.

The university hopes to receive twice as much space in return for its prime real estate in the centre of Fukuoka, according to the dean of one of the university's faculties, "with perhaps a few buildings included as well". But the site is hilly and will need levelling before the move, expected to be in about five years. The plan must first be approved by the Ministry of Education, Science and Culture and the finance ministry, but it seems likely to go ahead because it supports a government policy to improve the environment of Japan's national universities.

Tokyo University has similar plans to expand into the countryside. Next fiscal year, the university hopes to receive money for detailed plans to move several parts of the university from central Tokyo to Kashiwa, northeast of the capital in Chiba Prefecture. Among the plots of land the university hopes to sell is that occupied by the Institute of Solid State Physics in Roppongi, a popular night spot. Parts of the faculties of engineering and science also plan to move to the Kashiwa campus.

The first national university expected to sell land under the new amendment is Osaka University, which has already moved from central Osaka to Suita campus in the northern outskirts of the city. However, these plans may be affected by the recent bursting of Japan's 'bubble economy' which has sent land prices plummeting, particularly in the centre of cities. One of the deans of Tokyo University doubts that the university will be able to find a buyer in the present depressed economic climate. Fortunately, the new law allows the government to obtain loans for the relocations until the real estate market recovers.

David Swinbanks
Reforms accompany relocations

Fukuoka. As well as moving from the city to orange fields (see above), Kyushu University, like many of its counterparts elsewhere in Japan, will undergo major reform and reorganization as it tries to reinvigorate its research environment.

The college of general education, which provides two years of initial training for all students, will be dissolved. Some of the general education faculty members will move to a new graduate school while others will join faculties on the main campus.

There is a trend among Japan's national universities to eliminate the unpopular general education courses established during the US occupation of Japan after the Second World War. The general education classes are overcrowded and are often housed in cramped quarters. The quality of teaching is often low, and faculty have little time for research.

Large, multidisciplinary research groups (multi-koza) will be formed within the science and engineering graduate schools of Kyushu University instead of the present small groups (koza) run by one professor. The idea is to make the graduate research system more flexible and to encourage new fields of research; it is modelled on an initiative by Tokyo University (see Nature $\mathbf{3 5 1}$, $679 ; 1992)$

D.S.

\section{India threatened with Ioss of nuclear fuel}

New Delhi. The French government has threatened to stop supplying fuel for India's two nuclear power plants at Tarapur next year unless India signs the Nuclear Non-Proliferation Treaty (NPT) or allows international inspection of its facilities.

The French have supplied the Tarapur plants with enriched uranium fuel since 1983, three years after the United States prematurely ended an agreement to supply them with fuel for their lifetime, but the French agreement ends in 1993.

Although France had not signed the NPT when it began its shipments, it became a member last year. In recent months, France has told India that it cannot continue the shipments under the current agreement. India considers the NPT to be discriminatory and it refuses to allow inspections by the International Atomic Energy Agency, claiming them to be an infringement of sovereignty.

K.S. Jayaraman 